\title{
Letter \\ The diagnosis and management of pre-invasive breast disease: another point of view
}

\author{
Sunil Badve
}

Indiana University, Indianapolis, Indiana, USA

Correspondence: Sunil Badve (e-mail: sbadve@iupui.edu)

Published: 7 November 2003

Breast Cancer Res 2004, 6:E3 (DOI 10.1186/bcr740)

(C) 2004 BioMed Central Ltd (Print ISSN 1465-5411; Online ISSN 1465-542X)

I read with interest the series of articles on 'Pre-invasive breast disease' in the September and November issues of Breast Cancer Research [1-9]. Although each of the articles is well written, the series raises several issues and in places is contradictory.

Loss of heterozygosity ( $\mathrm{LOH}$ ) has been detected in invasive carcinomas, in ductal carcinoma in situ (DCIS), in atypical ductal hyperplasia (ADH) and in atypical lobular hyperplasia/lobular carcinoma in situ $[10,11]$. LOH has also been detected in much lesser frequency in ductal hyperplasia usual type, in normal breast [12] and in gynecomastia [13].

Two mutually contradictory conclusions can be drawn from this data. First, LOH studies indicate a progressive build-up of molecular abnormalities, which in some instances culminate in malignant transformation. Similar frequencies of $\mathrm{LOH}$ in $\mathrm{ADH}$ and in low-grade DCIS indicate a relationship close enough to justify merger of these entities (suggested by Pinder and Ellis [2]).

The second conclusion is that, since $\mathrm{LOH}$ is seen even in normal breast, it has no significance. This conclusion is supported by the distinct keratin profiles of ductal hyperplasia usual type and of ADH/DCIS [14]. Lesions called 'atypical hyperplasia' are either hyperplastic or neoplastic but are not precursory in nature, and the term ADH is best discarded (suggested by van de Vijver and Peterse [5]).

The morphological identification and distinction of ADH from DCIS is problematic to say the least. One can easily agree with van de Vijver and Peterse [5] in questioning the use of the term $A D H$ for lesions that have the morphological features of DCIS but are smaller than $2 \mathrm{~mm}$. Whatever our individual bias may be, it seems clear from the studies initiated by Page and colleagues [15] that there exists a lesion that is a marker of increased risk for breast cancer. This lesion is similar to atypical lobular hyperplasia/lobular carcinoma in situ and is distinct from DCIS in that cancers arising in patients with this lesion are not localized to the area of prior abnormality, but can arise anywhere in the same breast or in the contralateral breast. Although some forms of low-grade DCIS, such as micropapillary DCIS, can be multicentric, most DCIS is unicentric and cancers arising in patients with this condition seem to arise at the site of prior lesion. Whatever the molecular resemblance, this biologic behavior should be sufficient to merit the distinction of $\mathrm{ADH}$ from DCIS.

I agree that the term ADH is a misnomer as the lesion arises in terminal duct lobular units and not in 'true' ducts [15]. However, ADH still serves an important function of identifying a unique lesion that indicates an increase in risk for breast cancer and indicates that this risk, unlike that associated with DCIS, is bilateral. Combining ADH with low-grade DCIS, on the basis of the limited molecular data currently available, is premature.

\section{Competing interests}

None declared.

\section{References}

1. Evans A: The diagnosis and management of pre-invasive breast disease: radiological diagnosis. Breast Cancer Res 2003, 5:250-253.

2. Pinder SE, Ellis IO: The diagnosis and management of preinvasive breast disease: ductal carcinoma in situ (DCIS) and atypical ductal hyperplasia (ADH) - current definitions and classification. Breast Cancer Res 2003, 5:254-257.

3. Simpson PT, Gale T, Fulford LG, Reis-Filho JS, Lakhani SR: The diagnosis and management of pre-invasive breast disease: pathology of atypical lobular hyperplasia and lobular carcinoma in situ. Breast Cancer Res 2003, 5:258-262.

4. Schnitt SJ: The diagnosis and management of pre-invasive breast disease: flat epithelial atypia - classification, pathologic features and clinical significance. Breast Cancer Res 2003, 5:263-268. 
5. van de Vijver MJ, Peterse $\mathrm{H}$ : The diagnosis and management of pre-invasive breast disease: pathological diagnosis - problems with existing classifications. Breast Cancer Res 2003, 5: 269-275.

6. Nerurkar A, Osin P: The diagnosis and management of preinvasive breast disease: the role of new diagnostic techniques. Breast Cancer Res 2003, 5:305-308.

7. Purushotham AD: The diagnosis and management of preinvasive breast disease: problems associated with management of pre-invasive lesions. Breast Cancer Res 2003, 5:309-312.

8. Reis-Filho JS, Lakhani SR: The diagnosis and management of pre-invasive breast disease: genetic alterations in preinvasive lesions. Breast Cancer Res 2003, 5:313-319.

9. Jeffrey SS, Pollack JR: The diagnosis and management of preinvasive breast disease: the promise of new technologies in understanding pre-invasive lesions. Breast Cancer Res 2003, 5:320-328.

10. Stratton MR, Collins N, Lakhani SR, Sloane JP: Loss of heterozygosity in ductal carcinoma in situ of the breast. J Pathol 1995, 175:195-201.

11. Lakhani SR, Collins N, Stratton MR, Sloane JP: Atypical ductal hyperplasia of the breast: clonal proliferation with loss of heterozygosity on chromosomes $16 q$ and $17 p$. J Clin Pathol 1995, 48:611-615.

12. Deng G, Lu Y, Zlotnikov G, Thor AD, Smith HS: Loss of heterozygosity in normal tissue adjacent to breast carcinomas. Science 1996, 274:2057-2059.

13. Cornelio DA, Schmid-Braz AT, Cavalli LR, Lima RS, Ribeiro EM, Cavalli IJ: Clonal karyotypic abnormalities in gynecomastia. Cancer Genet Cytogenet 1999, 115:128-133.

14. Boecker W, Buerger H, Schmitz K, Ellis IA, van Diest PJ, Sinn HP, Geradts J, Diallo R, Poremba C, Herbst H: Ductal epithelial proliferations of the breast: a biological continuum? Comparative genomic hybridization and high-molecular-weight cytokeratin expression patterns. J Pathol 2001, 195:415-421.

15. Page DL, Dupont WD, Rogers LW, Rados MS: Atypical hyperplastic lesions of the female breast. A long-term follow-up study. Cancer 1985, 55:2698-2708.

\section{Correspondence}

Sunil Badve, Division of Surgical Pathology, Indiana University Hospital, Room UH 3465, 550 University Boulevard, Indianapolis, IN 46202, USA. Tel: +1 317274 1823; fax: +1 317274 5346; e-mail: sbadve@iupui.edu 